\title{
RelB upregulates PD-L1 and exacerbates prostate cancer immune evasion
}

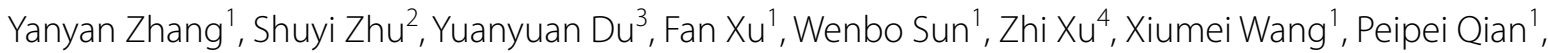 \\ Qin Zhang ${ }^{5^{*}}$, Jifeng Feng ${ }^{3^{*}}$ and Yong $\mathrm{Xu}^{1,2^{*}}$ (D)
}

\begin{abstract}
Background: The interaction between programmed death receptor (PD-1) and its ligand (PD-L1) is essential for suppressing activated T-lymphocytes. However, the precise mechanisms underlying PD-L1 overexpression in tumours have yet to be fully elucidated. Here, we describe that RelB participates in the immune evasion of prostate cancer (PCa) via cis/trans transcriptional upregulation of PD-L1.

Methods: Based on transcriptome results, RelB was manipulated in multiple human and murine PCa cell lines. Activated $\mathrm{CD} 4^{+}$and $\mathrm{CD} 8^{+} \mathrm{T}$ cells were cocultured with PCa cells with different levels of RelB to examine the effect of tumourous RelB on T cell immunity. Male mice were injected with murine PCa cells to validate the effect of RelB on the PD-1/PD-L1-mediated immune checkpoint using both tumour growth and metastatic experimental models.

Results: PD-L1 is uniquely expressed at a high level in PCa with high constitutive RelB and correlates with the patients' Gleason scores. Indeed, a high level of PD-L1 is associated with RelB nuclear translocation in AR-negative aggressive PCa cells. Conversely, the silencing of RelB in advanced PCa cells resulted in reduced PD-L1 expression and enhanced susceptibility of PCa cells to the T cell immune response in vitro and in vivo. Mechanistically, a proximal NF-KB enhancer element was identified in the core promoter region of the human CD274 gene, which is responsible for RelB-mediated PD-L1 transcriptional activation. This finding provides an informative insight into immune checkpoint blockade by administering RelB within the tumour microenvironment.
\end{abstract}

Conclusion: This study deciphers the molecular mechanism by which tumourous RelB contributes to immune evasion by inhibiting $T$ cell immunity via the amplification of the PD-L1/PD-1-mediated immune checkpoint.

\section{Background}

Prostate cancer $(\mathrm{PCa})$ is the most common malignant tumour and the leading cause of cancer death in men, with an estimated 1,276,000 new cases and 359,000

\footnotetext{
*Correspondence: yxu4696@njmu.edu.cn; fjif@vip.sina.com; zhangqin804@sohu.com

2 Jiangsu Key Lab of Cancer Biomarkers, Prevention and Treatment, Nanjing Medical University, Nanjing 211166, China

${ }^{3}$ Department of Medical Oncology, the Affiliated Cancer Hospital of Nanjing Medical University, Jiangsu Cancer Hospital \& Jiangsu Institute of Cancer Research, Nanjing 210009, China

${ }^{5}$ Department of Surgery, Jiangsu Cancer Hospital \& Jiangsu Institute of Cancer Research \& the Affiliated Cancer Hospital of Nanjing Medical University, Nanjing 210009, China

Full list of author information is available at the end of the article
}

deaths worldwide in 2018 [1]. Owing to improved early diagnosis and advanced therapeutic strategies, the mortalities of PCa have been appreciably decreased. Unfortunately, some PCa patients eventually develop more aggressive malignant forms resistant to traditional radiotherapy and chemotherapy, leading to poor prognosis [2]. Recently, the mutation rate identified in homologous recombination DNA repair genes showed as high as $20-25 \%$ in metastatic castration-resistant prostate cancer ( $\mathrm{mCRPC}$ ) and defects in the repair genes can sensitize PCa cells to Poly(ADP-ribose) polymerase inhibitors [3]. Similar results were also found in bladder cancer $[4,5]$. Notably, emerging evidence has demonstrated that enhancing the immune response is an effective 
therapeutic option for improving the survival of cancer patients [6]. Indeed, tumour-induced immunosuppression plays a pivotal role in tumour evasion from host immune surveillance, which provides a complementary approach to the treatment of tumours using immune checkpoint inhibitors [7]. Accordingly, multiple studies have focused on blocking immune checkpoints, such as targeting CTLA-4 and the PD-1/PD-L1 axis, which has been shown to restore or strengthen $\mathrm{T}$ cell antitumour immunity $[8,9]$. In particular, PD- $1 / \mathrm{PD}-\mathrm{L} 1$ is widely recognized as the best immune checkpoint target based on its therapeutic validation in prospective clinical outcomes, including subsets of solid tumours [10].

$\mathrm{PD}-1$, an important $\mathrm{T}$ cell co-inhibitory receptor, is expressed on the surface of antigen-stimulated $\mathrm{T}$ cells and plays a fundamental role in suppressing adaptive immune responses and promoting self-tolerance against $\mathrm{T}$ cell inflammatory activity. The activation of PD-1 prevents autoimmune diseases and impedes tumour suppression due to immunocompromise [11]. PD-1 has two known ligands, PD-L1 and PD-L2, of which PD-L1 is the dominant inhibitory ligand associated with immunotherapeutic responses within the tumour microenvironment [12]. As a critical checkpoint molecule in the regulation of the immune response, PD-1 is expressed in dendritic cells, T/B cells, tumour-associated macrophages, and myeloid-derived suppressor cells [13]. On the other hand, PD-L1 is highly expressed in a variety of cancer cells, which leads to tumour immune evasion as they interact with PD-1 [14]. Since the PD-L1/PD-1 interaction is essential for inducing $\mathrm{T}$ cell apoptosis and the immune checkpoint response, targeting the PD-1/PD-L1 axis is thought to be a feasible approach for treating aggressive tumours [15].

Inflammatory signalling regulates the transcription of PD-L1. In particular, IFN- $\gamma$, a proinflammatory cytokine, is recognized as the most prominent inducer of PD-L1 [16]. Additionally, several other cytokines can also upregulate PD-L1, including TNF- $\alpha$, IL-1 $\beta$, IL-4, IL-10, and IL-17 [17]. Multiple transcription factors involved in the JAK/STAT, RAS/MAPK, and PTEN-PI3K/AKT pathways participate in the regulation of PD-L1, such as STAT1, STAT3, IRF1, IRF3, HIF-1 $\alpha$, MYC, JUN, BRD4, and NF- $\kappa B$ [18]. Since NF- $\kappa B$ plays a substantial role in inflammatory and immune responses [19], NF- $\mathrm{kB}$ is considered to influence PD-L1 expression. RelA (p65) has been reported to upregulate PD-L1 expression in lung cancer cells in response to TNF- $\alpha$ stimulation [20].

$\mathrm{NF}-\mathrm{KB}$ plays an essential role in cancer progression and therapeutic resistance [21]. In general, NF- $\mathrm{kB}$ activation is mediated by two major pathways, i. e., the canonical pathway and the noncanonical pathway. The canonical pathway quickly responds to many exogenous stimulants and leads to the nuclear translocation of the p50:RelA dimer followed by ІкB phosphorylation and degradation [22]. The noncanonical pathway is gradually but persistently activated by processing p100:RelB into the p52:RelB dimer [23]. In addition to the canonical pathway that is widely recognized to be critical for regulating the inflammatory response, the noncanonical pathway is thought to be a key regulator of the immune response [24]. Nevertheless, in contrast to the well-studied canonical pathway in cancer development, the role of the noncanonical pathway in cancer remains to be fully elucidated.

RelB was initially identified in B-cells and the RelBactivated noncanonical NF- $\mathrm{KB}$ pathway has been shown to respond to antigen presentation by DCs, which is associated with inflammation and excessive immune cell infiltration [25-27]. Furthermore, RelB has been implicated in cancer progression, particularly in sex hormone-related cancers, including PCa, breast cancer and endometrial cancer [28-30]. We have recently shown that a high constitutive level of RelB is correlated to $\mathrm{PCa}$ radioresistance [31]. The present study further demonstrates a cis/trans transcriptional regulatory mechanism by which RelB upregulates PD-L1 in PCa cells. Accordingly, the repression of tumour-derived RelB can promote the $\mathrm{T}$ cell immune response by downregulating PD-L1.

\section{Methods \\ PCa patients}

The Nanjing Medical University Affiliated Cancer Hospital (Nanjing, China) collected fresh tumour tissues from newly diagnosed PCa patients before chemotherapy or radiotherapy. The Ethics Committee of Nanjing Medical University approved the study protocol with written informed consent forms obtained from patients enrolled in this study. From a Gleason score of 5 to 9, each group containing 8-10 cases was selected. Total 46 cases of PCa tumour tissue v.s 10 cases normal prostate tissue were analysed to examine the correlation between RelB and PD-L1 expression using immunohistochemistry (IHC) with monoclonal antibodies against human RelB and PD-L1 (Cell Signalling Tech., USA). Briefly, the tissues were fixed in paraffin-embedded slides and then dewaxed with xylene. After washing with ethanol, the tissue slides were further rehydrated by rinsing with $\mathrm{dH}_{2} \mathrm{O}$. For IHC, the tissue slides were soaked in 5\% BSA buffer for $1 \mathrm{~h}$ and then incubated with 400x diluted primary antibodies within $5 \%$ BSA buffer at $4{ }^{\circ} \mathrm{C}$ overnight. After washing with PBS, the tissue slides were incubated with a biotinylated secondary antibody at room temperature for 30 min. After washing with BPS, a DAB Substrate Kit (Cell Signalling Tech., USA) was used to observe immunostaining images under a microscope. The intensity 
of IHC staining was scored as negative (score 0 ), weak (1), medium (2), and strong (3). Total cell positivity was scored as the percentage of positive cells, including no positive cells (0), <25\% (1), $25-50 \%$ (2), $50-75 \%$ (3), and $>75 \%$ (4). The "H-score" was calculated using $\sum \mathrm{pi}$ $(i+1)$ for all slides, in which pi represented the percentage of positive and $i$ represented the staining intensity.

\section{Mice}

Animal experiments were performed according to the Institutional Animal Care and Use approved by the Research Committee of Nanjing Medical University (No. IACUC-1901031). For the mouse xenograft PCa tumour growth experiment, five-week-old male C57BL/6 mice (Beijing Vital River Laboratory Animal Technology Co., Ltd., China) were randomly divided into several groups. The mice were subcutaneously injected with $2.5 \times 10^{5}$ RM-1 cells with different levels of RelB and PD-L1 into the left flank. The formed tumours were measured using digital callipers every other day and tumour volume was calculated using a standard formula $\left(\mathrm{V}=0.52 \times \mathrm{AB}^{2}\right.$, where $A$ and $B$ represent the diagonal tumour lengths) at 7,14 and 21 days after the cell injection. $\mathrm{CD}^{+}$and $\mathrm{CD}^{+}$ $\mathrm{T}$ cells were isolated from mouse blood samples and analysed by flow cytometry. The mice were finally sacrificed and tumour tissues were excised for immunoblotting and IHC. For the xenograft PCa tumour metastasis experiment, $5 \times 10^{4} \mathrm{RM}-1$ cells were injected into mice through the tail vein. The mice were euthanized four weeks later to remove lung tumour tissues and analysed by IHC and immunoblots. Additionally, $\mathrm{CD}^{+}{ }^{+}$and $\mathrm{CD}^{+} \mathrm{T}$ cells isolated from mouse spleen tissues were analysed by flow cytometry.

\section{T cell preparation}

Whole blood samples were obtained from healthy donors according to the institutional guidelines with informed consent. Peripheral blood mononuclear cells (PBMCs) were isolated by density centrifugation using Ficoll gradient separation. The cells were washed three times with PBS and suspended in RPMI 1640 media (Gibco, USA). In addition, mouse $\mathrm{T}$ cells were isolated from peripheral blood samples and spleen tissues derived from male C57BL/6 mice. The pellets were lysed within RBC lysis buffer for $10 \mathrm{~min}$ to remove red blood cells and the tissues were ground and then filtered to remove tissue debris. The cells were cultured in a $\mathrm{T}$ cell preconditional RPMI 1640 media supplemented with 1000x mercaptoethanol (Gibco), 100x penicillin-streptomycin (Gibco), 100X glutamine-MAX (Gibco) and 10\% heat-inactivated FBS (Gibco). Single cells were collected by centrifugation and $\mathrm{T}$ cells were stimulated in media containing $2 \mu \mathrm{g} / \mathrm{ml}$
anti-CD3, $3 \mu \mathrm{g} / \mathrm{ml}$ anti-CD28 and $200 \mathrm{U} / \mathrm{ml}$ IL-2 (Biolegend, Inc., USA) for $24 \mathrm{~h}$ prior to coculture with PCa cells.

The cultured $\mathrm{T}$ cells were analysed by flow cytometry before and after coculture with PCa cells. APC-conjugated anti-human CD4/mouse antibody (Biolegend) and PE-conjugated anti-human CD8/mouse antibody (BioLegend) were used to stain CD4 or CD8 cells. The labelled cells were analysed by a BD FACSCalibur flow cytometer (BD Sciences, USA). In addition, to analyse T cell proliferation, the $\mathrm{T}$ cells were labelled with $5 \mu \mathrm{M}$ CFSE (Biolegend) for $20 \mathrm{~min}$ at $37^{\circ} \mathrm{C}$ in darkness. Cell staining was blocked by adding cell culture media containing $10 \%$ FBS. Flow cytometry data were further analysed with FlowJo software and Modfit software.

\section{RelB manipulation in PCa cells}

Human PCa cell lines (PC-3 and DU-145) and mouse PCa cell lines (RM-1) were purchased from the American Type Culture Collection (ATCC, USA). The cell lines were cultured in the recommended media containing 10\% FBS and $1 \%$ penicillin/streptomycin. The cells were treated with IFN- $\gamma$ (Novus, USA) to induce PD-L1 expression. RelB was silenced in PC-3 and DU-145 cells by transfection of a plasmid-carrying shRNA duplex targeting RelB (RiboBio Co., Ltd., China) and stable cell clones were selected using G418 (Invitrogen, USA). Additionally, to restore RelB activity in RelB-defective PC-3 cells, a RelB cDNA driven by the CMV promoter in pCMV-Script vector (Stratagene, USA) was transiently transfected into RelB-silenced cells. Furthermore, RelB was knocked out (RelB-KO) in RM-1 cells using a CRISPR/Cas9-based gene-editing system. Briefly, RM-1 cells were transfected with a Cas9-single guide RNA (sgRNA) expression plasmid targeting RelB (sgRNA, 5'-GACGAATACATTAAG GAGAA-3'), followed by puromycin selection. In addition, PD-L1 cDNA was cloned into the pcDNA plasmid and then transfected into RelB-KO RM-1 cells, followed by hygromycin B (Invitrogen) selection to generate a stable cell line.

\section{Immune cytotoxicity}

The effect of activated $\mathrm{T}$ cells on the survival of $\mathrm{PCa}$ cells was determined using cell counting and clonogenic assays, respectively. After coculture with activated $\mathrm{T}$ cells at a 1:10 ratio for 3 days, PCa cells were seeded into 96-well plates at a density of $10^{3}$ cells/well and then cultured for 2 days. The cells were treated with CCK- 8 reagent (Dojindo Mol. Tech., Japan), and cell viability was measured as the optical density at $450 \mathrm{~nm}$. For the clonogenic assay, PCa cells were treated with an anti-PDL1 mAb (Abcam, USA) prior to coculture with activated T cells. Thereafter, 100-200 PCa cells were plated in 6-well plates and continuously cultured to allow colony 
formation. After washing with $1 x$ PBS twice, the colonies were stained with $1 \%$ crystal violet dye for $30 \mathrm{~min}$ to form visible cell clones. The cell survival fractions were calculated based on the number of colonies divided by the number of cells efficiently plated.

\section{RNA-seq}

The RNA sequencing libraries were constructed by Vazyme Biotech Co., Ltd. (Nanjing, China) using a VAHTS mRNA-seq v2 Library Prep Kit for Illumina. The cDNA libraries were sequenced on an Illumina HiSeq X Ten platform with a $150 \mathrm{bp}$ paired-end module. The raw reads were filtered by removing reads containing adapter, poly- $\mathrm{N}$ and low-quality read for subsequent analysis. Cuffdiff (v1.3.0) was used to calculate FPKMs for coding genes in each sample. Genes with corrected $p$-value less than 0.05 and the absolute value of $\log 2$ (fold change) greater than or equal to 1 were considered as significantly differentially expressed. Custom scripts in $\mathrm{R}$ software were used for clustering and heatmap analysis (https://www.r-project.org). In addition, the altered mRNA expression profile in shRelB cells vs. shCtrl cells was analysed using KEGG pathway enrichment (https:// david.ncifcrf.gov).

\section{Immunofluorescence}

PCa cells were seeded in confocal dishes at a density of $2 \times 10^{3}$, washed with cold $1 \times$ PBS and fixed with $4 \%$ paraformaldehyde in PBS for $15 \mathrm{~min}$. Subsequently, the cells were permeabilized with $1 \mathrm{x}$ PBS containing $0.5 \%$ Triton $\mathrm{X}-100$ for $20 \mathrm{~min}$ and then blocked for $30 \mathrm{~min}$. The cells were incubated with primary antibodies against RelB and PD-L1 at $4{ }^{\circ} \mathrm{C}$ overnight and then probed with Alexa Fluor $^{\circledR} 647$ conjugated (Cell Signalling Tech., USA) or Alexa Fluor ${ }^{\circledR} 488$ conjugated (Abcam, UK) secondary antibodies for $1 \mathrm{~h}$ at room temperature. After counterstaining with DAPI (Invitrogen) for $5 \mathrm{~min}$, fluorescence was visualized and captured using a TCS SP5 MP confocal microscope (Leica Microsystems, Inc., USA).

\section{NF-kB binding activity}

Nuclear proteins were extracted from PCa cells using a nuclear and cytoplasmic protein extraction kit (Beyotime Biotech.) according to the manufacture's instruction. The nuclear extracts $(50 \mu \mathrm{g})$ were subjected to an NF-kB binding activity kit containing the consensus sequence of the NF- $\mathrm{kB}$ element as a standard probe (Abcam, USA) to measure the NF- $\mathrm{kB}$ binding activity based on the manufacturer's protocol.

\section{Luciferase reporter assay}

A 2000-bp 5'-flanking region of the human CD274 gene containing a core promoter containing putative multiple
NF- $\mathrm{kB}$ elements was cloned into the pGL3 vector (Promega, USA) to drive the luciferase reporter gene. Subsequently, a functional NF-kB binding site was mutated using a site-directed mutagenesis system (Thermo Fisher, USA). The luciferase reporter constructs were cotransfected with $\beta$-gal into PC-3 cells using Lipofectamine (Invitrogen). After $48 \mathrm{~h}$, the luciferase activity was quantified by a luciferase assay system (Promega, USA) using a luminometer (Berthold Tech., Germany). The $\beta$-gal activity was quantified using microplate readers (BioTek, USA). NF- $k B$-mediated transcriptional enhancement was estimated by the $\beta$-gal-normalized luciferase response.

\section{ChIP}

RelB binding to the NF- $\mathrm{kB}$ elements in the human CD274 gene was examined by chromatin immunoprecipitation (ChIP) using a SimpleChIP Enzymatic Chromatin IP Kit (Cell Signalling Tech.). A RelB antibody (Santa Cruz Biotech., USA) was applied to pull down chromatin from nuclear extracts isolated from PCa cells. Chromatin without antibody pulldown served as the input control, and IgG (Santa Cruz Biotech.) served as a negative antibody control. The pulled-down fragments were quantified by PCR using relative primers (Table S1). The amounts of the pulled-down fragments were assessed by normalization to the input control.

\section{EMSA}

Electrophoretic mobility shift assay (EMSA) was further performed to confirm the specific RelB binding to the human CD274 promoter. A double-stranded DNA fragment containing the native or mutated NF- $\mathrm{kB}$ binding site were synthesized and annealed. The $3^{\prime}$ - terminus of the upper strand was labelled using a probe biotinlabelling kit (Beyotime Biotech., China). EMSA was conducted by incubating the probes with PC-3 cell-derived nuclear proteins within a chemiluminescent EMSA kit (Beyotime) according to the manufacturer's instructions. The unlabelled wild-type and mutated probes were used as competitors to quantify the specific binding activity. A RelB antibody was used to eliminate the binding activity. The EMSA image was visualized using a BioRad GelDoc $\mathrm{XR}+$ system. The sequences of the wild-type and mutant probes are listed in Table S1.

\section{RT-qPCR}

The mRNA levels of RelB and PD-L1 were quantified by reverse transcription-quantitative PCR (RT-qPCR). Total RNA was extracted from PCa cells using the TRIzol reagent and cDNA was reversely transcribed from mRNA using a PrimeScript ${ }^{\mathrm{TM}}$ RT reagent kit (Takara Inc., Japan) according to the manufacturer's instructions. cDNA was quantified by qPCR with SYBR Premix Ex Taq II (Takara 
Inc.) using a LightCycle System (Roche, USA). The mRNA level of PD-L1 was estimated by normalizing to GAPDH mRNA. Sequences of the specific PCR primers for PD-L1 and GAPDH are listed in Table S1.

\section{Immunoblots}

PCa tumour tissues and cells were lysed in RIPA lysis buffer containing $1 \mathrm{mM}$ PMSF protein inhibitor (Santa Cruz Biotech.). Cellular and nuclear extracts $(50-100 \mu \mathrm{g})$ were separated on $10 \%$ SDS-polyacrylamide gels and then transferred to PVDF membranes. The membranes were subsequently incubated overnight at $4{ }^{\circ} \mathrm{C}$ with the primary antibodies against RelA, RelB, PCNA, and GAPDH (Cell Signalling Tech.), and anti-human PD-L1, antimouse PD-L1 (Abcam). The membranes were washed three times with TBST buffer and incubated at room temperature for $2 \mathrm{~h}$ with HRP-conjugated secondary antibody (Santa Cruz Biotech. USA). The immunoblots were visualized using an enhanced chemiluminescence detection system (Bio-Rad, USA). The intensities of the blots were quantified using Quantity One software and protein expression was normalized to loading controls such as $\beta$-actin and GAPDH.

\section{Bioinformatics}

Oncomine $^{\mathrm{TM}}$ (https://www.oncomine.org) and TCGA (https://www.cancer.gov/about-nci/organization/ccg/ research/structural-genomics/tcga) datasets were examined to assess the association of RelA, RelB or PD-L1 expression profiles with cancer progression and the correlation of RelA/RelB to PD-L1 was analysed to estimate the possibility that NF- $\mathrm{kB}$ regulates PD-L1 expression in tumours.

\section{Statistics}

The results are presented as the mean \pm standard deviation (SD) from at least three replicates. Significant differences between the experimental groups were analysed by unpaired Student's t-test. One-way analysis of variance (ANOVA) followed by Dunnett's or Bonferroni's multiple comparison test was performed using Prism (GraphPad, San Diego, USA). Statistical significance was accepted at $P<0.05$.

\section{Results}

\section{The constitutive levels PD-L1 and RelB are correlated with the aggressiveness of $\mathrm{PCa}$}

RelB is associated with PCa and breast cancer progression $[29,30]$. In consideration of the putative role of RelB in the regulation of cancer immune escape, we examined the Oncomine ${ }^{\mathrm{TM}}$ and TCGA datasets to enrich the potential relationship between PD-L1 and RelB signatures in cancer progression. PD-L1 is uniquely expressed at high levels in multiple cancer tissues compared to their corresponding normal tissues (Fig. S1a). In addition, the correlation of PD-L1 with RelA and RelB in PCa was assessed. The results indicated that PD-L1 is more highly associated with RelB than RelA in PCa tumour tissues, but no clear correlation was found in peritumoral tissues (Fig. S1b). Interestingly, similar results were observed in breast cancer, thus indicating that the noncanonical NF- $\kappa B$ pathway is critical for developing sex hormonerelated cancers (Fig. S1c). In contrast, the correlation of PD-L1 with RelA is higher than that of RelB in lung cancer. There was no apparent relationship of PD-L1 with RelA or RelB in liver cancer (Fig. S1d-e).

To verify whether the correlation of PD-L1 and RelB is also associated with the aggressiveness of $\mathrm{PCa}$, tumour and normal prostate tissues were examined by IHC with specific antibodies against RelB and PD-L1. As expected, PD-L1 and nuclear RelB were consistently elevated, which corresponded to an increase in patients' Gleason scores (Fig. 1a-d). The correlation between PD-L1 and RelB was associated with the pathological grades of tumour tissue samples (Fig. 1e). Thus, the results are consistent with the results from the Oncomine ${ }^{\mathrm{TM}}$ database and suggest that RelB may participate in the regulation of the CD274 gene expression during PCa progression.

\section{RelB upregulates PD-L1 expression in PCa cells}

Although the activation of the RelA-based canonical NF- $\mathrm{KB}$ pathway is involved in chemo- and radiotherapymediated PD-L1 induction in cancer cells [32, 33], there is no evidence showing that the RelB-based noncanonical pathway contributes to PD-L1 expression in cancers. To elucidate the effect of RelB on PCa immune evasion, RelB was silenced in two aggressive AR-negative PCa cell lines (PC-3 and DU-145) using a lentiviral shRelB expressing construct. The reduction of NF- $\mathrm{kB}$ binding activity in RelB-silenced cells was further confirmed. However, since other NF- $\mathrm{kB}$ members can also bind to the probe with the consensus NF- $\mathrm{BB}$ sequence, the effect of RelB silencing on total NF- $\mathrm{KB}$ binding activity was diluted, especially in DU-145 cells (Fig. 2a). RNA-Seq was applied to analyse mRNA expression profiles in the RelB-silenced PC-3 cells. The expression profiles of transcripts relevant to cytokine/chemokine production, inflammatory signalling pathways, and immune responses were selected, as illustrated in Fig. 2b. Compared to the scramble control cells, most mRNA expression levels were reduced in response to the silencing of RelB. KEGG-enriched signalling pathway analysis showed that the silencing of RelB led to reductions in advanced $\mathrm{PCa}$-associated cytokines/ chemokines (Fig. S2a). Inflammation recognition-associated TLRs, NLRs and LTM were also decreased in RelBsilenced cells (Fig. S2b). Additionally, the silencing of 


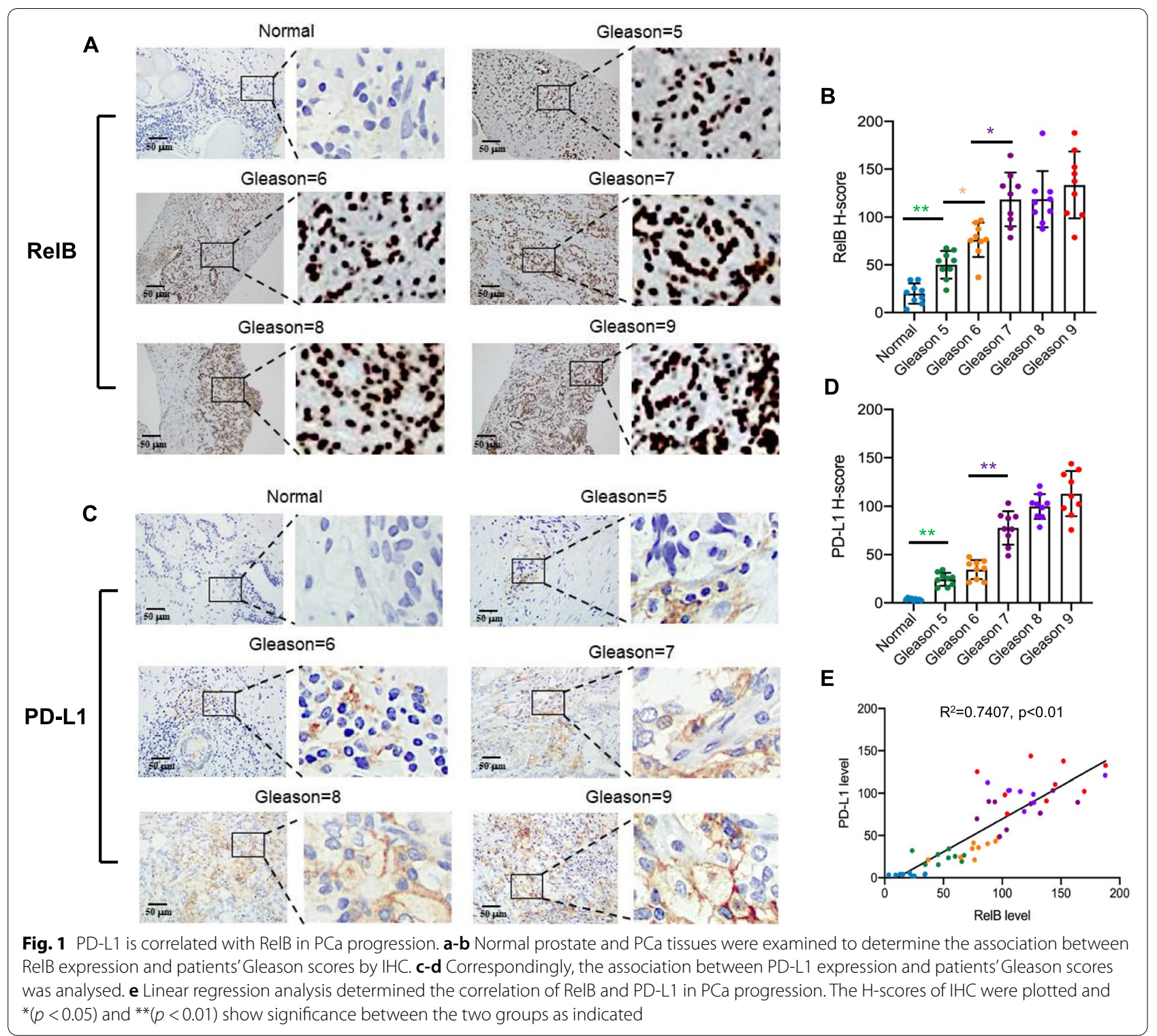

RelB in PCa cells led to the inhibition of receptors associated with immune response (Fig. S2c). Furthermore, the mRNA expression profiles related to the immune response in the RelB-silenced cells are listed in Table S2. Remarkably, the mRNA level of the CD274 gene was decreased in the RelB-silenced PC-3 cells.

To verify that RelB is able to regulate PD-L1 in PCa cells, the mRNA and protein levels of PD-L1 in RelBsilenced PC-3 and DU-145 cells were quantified. RelB was efficiently knocked down in the two cell lines, but no change in RelA expression was observed. Consistent with the decline of RelB, PD-L1 mRNA and protein levels were also reduced (Fig. 2c-d). In addition, IFN- $\gamma$ remarkably induced PD-L1 expression in PC-3 cells, but the induction was alleviated when RelB was silenced (Fig. 2e). Consistent with the decreased level of nuclear RelB, the induction of PD-L1 protein was impeded (Fig. 2f). The correlation of nuclear RelB and cytosolic PD-L1 was further confirmed by confocal microscopy (Fig. 2g). These results suggested that IFN- $\gamma$ induces PD-L1 expression partially via RelB-mediated transcriptional activation.

\section{A proximal NF-KB element was identified to be responsive to RelB-mediated the CD274 gene transcriptional regulation}

Although several lines of study have demonstrated that NF- $\mathrm{KB}$ signalling regulates PD-L1 expression, there is a lack of experimental evidence that NF- $\mathrm{kB}$ directly 


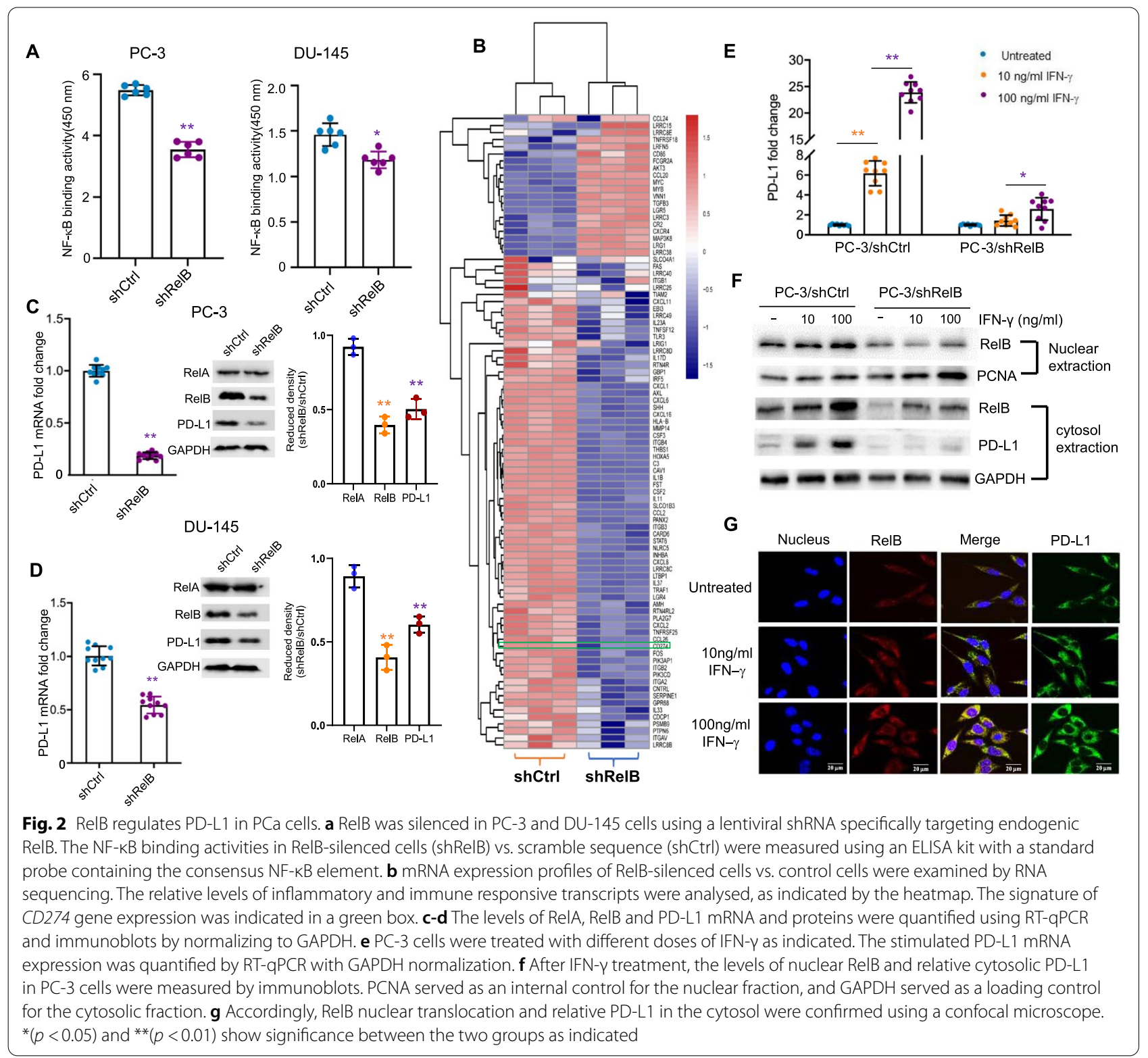

regulates PD-L1 expression in a cis/trans transcriptional regulatory manner. To elucidate how RelB regulates CD274 gene expression, a 2000-bp 5'-flanking fragment region containing a core promoter was cloned to drive luciferase reporter gene expression. Luciferase activity was reduced in RelB-silenced PC-3 cells (Fig. 3a). Additionally, the IFN- $\gamma$-induced reporter response declined when RelB was silenced (Fig. 3b). Three putative NF-kB binding sites (E1, E2, E3) located in the $5^{\prime}$-finking region were identified by analysing the Jaspar transcription factor database (http://jaspar.genereg.net). Accordingly, a ChIP assay was performed to verify each binding site using a RelB antibody. As shown in Fig. 3c, the proximal site (E3) appeared to be more susceptible to ChIP than E2 and distant E1 sites. The amount of E3 pull-down element was consistently reduced when chromatin extracted from RelB-silenced cells was used (Fig. 3d). Moreover, RelB binding to the E3 site was validated by EMSA. The nuclear extract was capable of shifting the probe containing the E3 site but not the mutant E3 site. An unlabelled probe was able to compete with E3 binding, but an unlabelled mutant probe was found to have no such competition. In addition, the RelB antibody was able to reduce the E3 binding activity (Fig. 3e). Furthermore, cell transfection with the mutated E3 site resulted in a reduction in the RelB-activated reporter response 


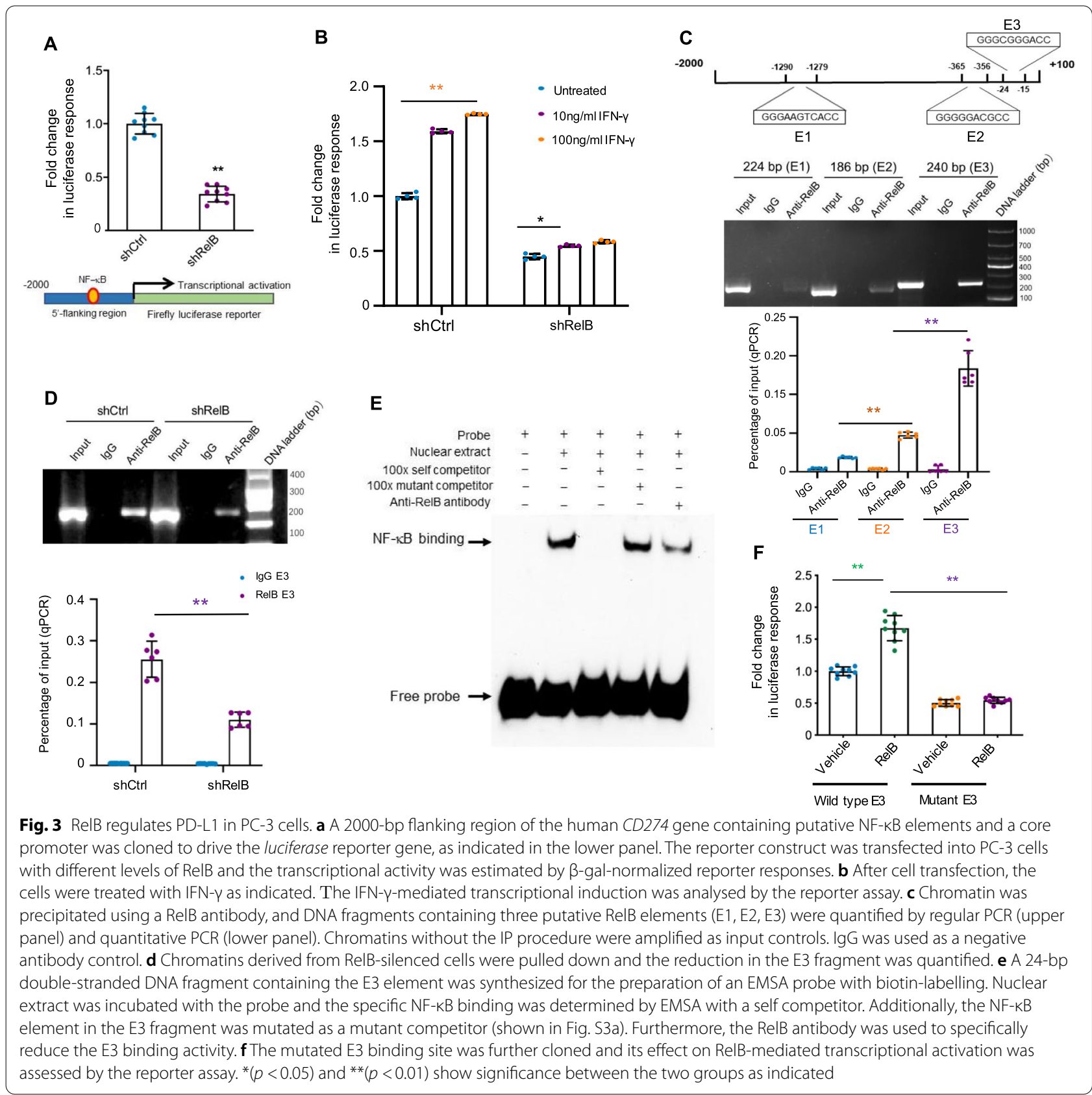

(Fig. S3a and Fig. 3f). Altogether, these results suggest that RelB transcriptionally regulates the human CD274 gene expression via a proximal NF- $\kappa B$ element located in the core promoter region, which is conserved in humans, mice and rabbits (Fig. S4a-b).

\section{Tumor-derived RelB contributes to inactivation of $\mathrm{CD} 4^{+}$ and $\mathrm{CD}^{+} \mathrm{T}$ cells}

Cancer immunotherapy aims to promote the cytotoxic effect of $\mathrm{T}$ lymphocytes within the tumour microenvironment. The signalling process is mainly relayed from $\mathrm{CD}_{4}^{+}$and $\mathrm{CD}^{+} \mathrm{T}$ cells by specific dendritic cells to optimize the immune response of $\mathrm{T}$ lymphocytes [34,35]. Thus, it is important to define the immune responsiveness of T cells to RelB-depleted PC-3 cells. To this end, we collected blood samples and isolated primary $\mathrm{T}$ cells from healthy donors who participated in this study. $\mathrm{T}$ cells were activated by pretreatment with anti-CD3, anti-CD28 and IL-2, and then cocultured with RelB-silenced PC-3 cells. The percentages of $\mathrm{CD}^{+}$and $\mathrm{CD}^{+} \mathrm{T}$ cells and their 
proliferation were quantified by flow cytometry with relative specific antibodies and CFSE dye. The results showed that stimulation by CD3 and CD28 efficiently increased the numbers of $\mathrm{T}$ cells. Interestingly, coculture with $\mathrm{PC}-3$ cells significantly reduced the activated $\mathrm{CD} 4^{+}$and $\mathrm{CD} 8^{+} \mathrm{T}$ cells, but its effect was alleviated when RelB was depleted in PC-3 cells (Fig. 4a-b). In addition, the proliferation of $\mathrm{CD}^{+}$and $\mathrm{CD}^{+} \mathrm{T}$ cells was consistently increased by stimulation but further precluded after coculturing with PC-3 cells. However, the inhibitory effect of PC-3 cells on T cell activation was favourably diminished by abrogating RelB (Fig. 4c-d).

Furthermore, to test whether tumourous RelB promotes $\mathrm{T}$ cell immune compromise by increasing PD-L1, the survival of PC-3 cells was quantified by clonogenic assay after coculture. The activated $\mathrm{T}$ cells efficiently eliminated the PC-3 cell colony number compared to the no coculture control. Intriguingly, the $\mathrm{T}$ cell immune response was further enhanced when RelB was silenced in PC-3 cells, which suggests that the high level of RelB in PC-3 cells contributes to immune evasion (Fig. 4e). Moreover, RelB was restored in lentivirus-mediated RelB-silenced PC-3 cells by transiently transfecting a human RelB cDNA expression construct into the cells (Fig. S5a). After coculture with activated T cells, the cancer cell survival rate fully recovered as RelB expression was restored (Fig. S5b). Accordingly, the numbers of active $\mathrm{CD} 4^{+}$and $\mathrm{CD} 8^{+} \mathrm{T}$ cells were apparently reduced by increasing RelB in the cancer cells (Fig. S5c-e).

\section{RelB deprivation enhances immune checkpoint blockade by an anti-PD-L1 inhibitor}

Meanwhile, a CRISPR/Cas9 gene-editing system was applied to knock out RelB in murine PCa RM-1 cells to verify that RelB contributes to immune evasion in vivo. Additionally, mouse PD-L1 was ectopically expressed in

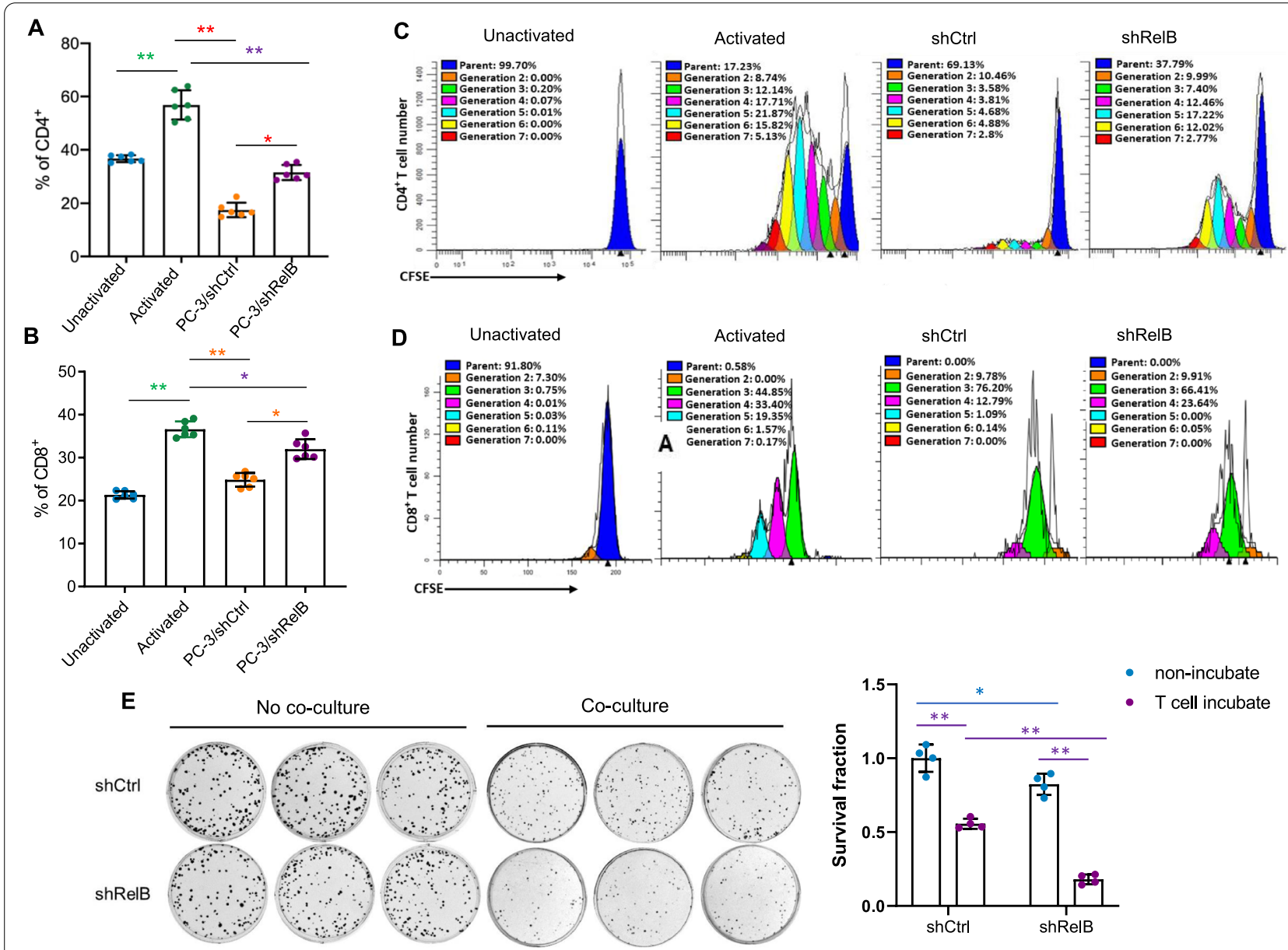

Fig. 4 Silencing RelB in PC-3 cells enhances the immunities of $C D 4^{+}$and $C D 8^{+} T$ cells. $\mathbf{a}-\mathbf{b}$ PC-3 cells were cocultured with activated T cells derived from human PBMCs. $\mathrm{CD}^{+}$and $\mathrm{CD} 8^{+}$T cells were quantified by flow cytometry using the relevant antibodies. c-d Subsequently, the proliferation of $\mathrm{CD}^{+}$and $\mathrm{CD} 8^{+} \mathrm{T}$ cells was analysed by flow cytometry. The percentage of each generation (cell division) was plotted. e After coculture with activated T cells, the survival rate of PC-3 cells was measured using a clonogenic assay. ${ }^{*}(p<0.05)$ and ${ }^{* *}(p<0.01)$ show significance between the two groups as indicated 
RelB-KO cells to restore immune suppression (Fig. S3b and Fig. 5a). NF- $\mathrm{kB}$ binding activity was measured in gene manipulated RM-1 cells (Fig. 5b). T cells were prepared from mouse spleens and then activated by CD3 and CD28 stimulation before coculturing with RM-1 cells (Fig. 5c). Consistent with the above results from PC-3 cells, RelB$\mathrm{KO}$ cells were more susceptible to $\mathrm{T}$ cells than were the control cells, but T-cell activation was further eliminated by enforced expression of PD-L1 in RelB-KO cells (Fig.
S6a). Similarly, coculture with RelB-KO cells led to recovered $\mathrm{CD} 4^{+}$and $\mathrm{CD} 8^{+} \mathrm{T}$ cells compared to coculture with RM-1 cells. In turn, the RelB-KO effect was further attenuated by expressing PD-L1 (Fig. S6b-c). In addition, the proliferation of $\mathrm{CD}_{4}^{+}$and $\mathrm{CD} 8^{+} \mathrm{T}$ cells further confirmed that $\mathrm{T}$ cell growth was virtually regulated by administrating RelB and PD-L1 in RM-1 cells (Fig. S6d-e).

Moreover, after coculture with activated T cells, RM-1 cells were treated with an anti-PD-L1 mAb. The results showed

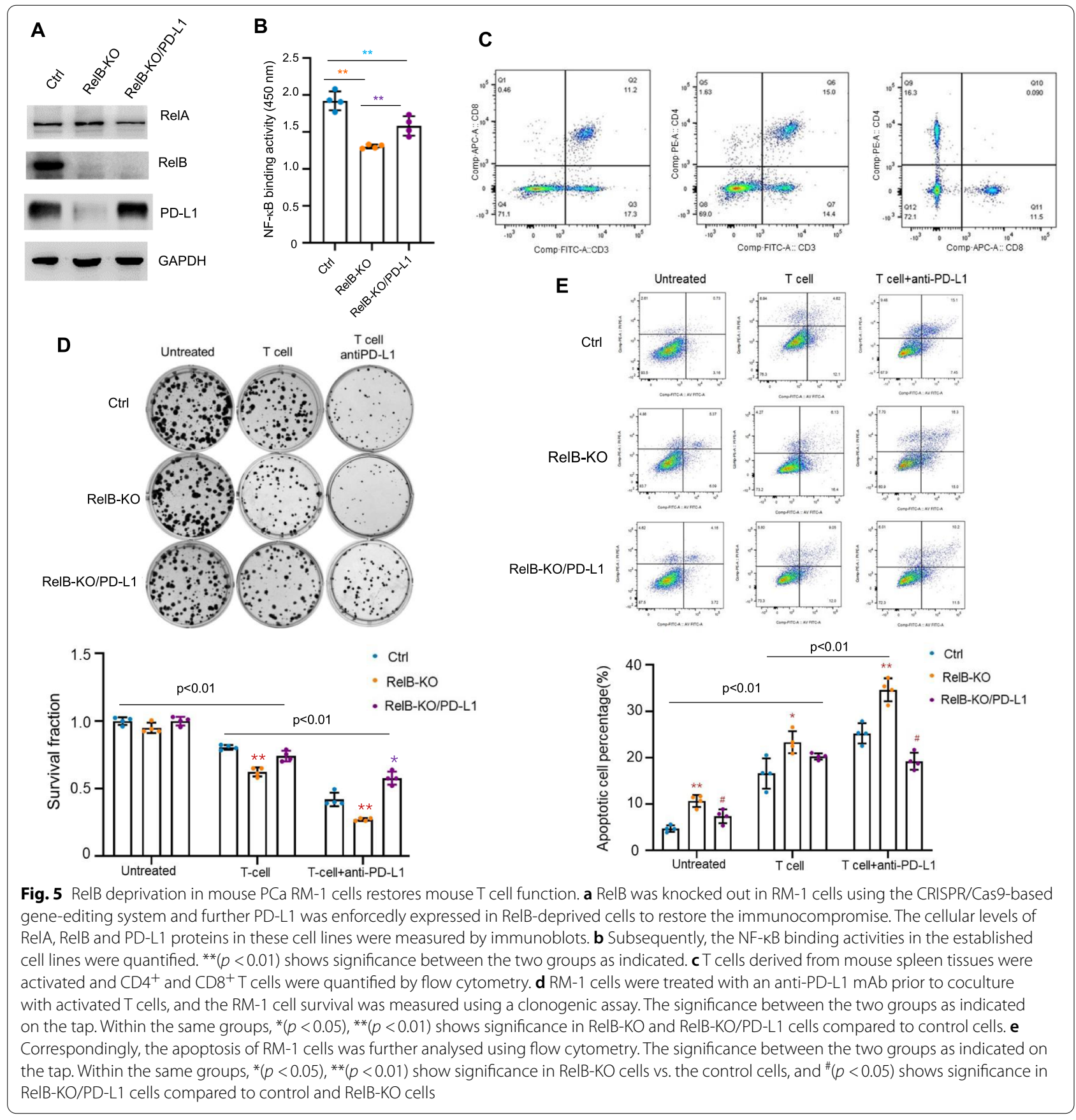


that the mAb dramatically enhanced the immune response of the T cells. Notably, RelB deprivation further enhanced $\mathrm{mAb}$ therapeutic efficiency. Nevertheless, the enforced expression of PD-L1 in the RelB-KO cells led to partial rescue of the cells (Fig. 5d). Correspondingly, the apoptotic cell rate was increased in RelB-KO cells treated with $\mathrm{T}$ cells plus an anti-PD-L1 inhibitory $\mathrm{mAb}$, but the effect was further alleviated as the PD-L1 level was elevated (Fig. 5e). These results suggest that the immune checkpoint blockade of PD-1/PD-L1 can be modulated by manipulating RelB.

\section{RelB contributes to PCa tumour immune evasion in mice}

A mouse tumour xenograft model was applied to define the role of RelB in the immune checkpoint of PD-1/PD-L1. RM-1, RM-1:RelB-KO and RM-1:RelB-KO/PD-L1 cell lines were used for tumour formation by subcutaneous injection into mice. In the control group, 3-5 days after injection, tumours were formed and then rapidly grew to reach the maximal tumour volume $\left(3000 \mathrm{~mm}^{3}\right)$ within three weeks. In contrast, tumour formation in the RelB-KO group was delayed and tumour growth was also slow. Nevertheless, the tumour growth in the RelB-KO/PD-L1 group was restored due to increased PD-L1 (Fig. 6a-b). All mice were sacrificed when the average tumour volume in the control group reached the maximum and tumour tissues were excised. Regardless of endogenous mouse PD-L1, the levels of PD-L1 in RelB-KO tumours were significantly reduced, but the levels were raised in RelB-KO/PD-L1 tumours (Fig. 6c-d). According to the manipulated PD-L1, the levels of CD4 and CD8 proteins increased via knockout of RelB, but the levels further decreased as PD-L1 was expressed (Fig. 6e). In addition, mouse serum samples were collected for T-cell activation (Fig. S7a). Compared to the control group, the numbers of $\mathrm{T}$ cells were increased in the RelBKO group (Fig. S7b). After tumour formation, the amounts of $\mathrm{CD}^{+}$and $\mathrm{CD}^{+} \mathrm{T}$ cells slightly increased, but in turn, they rapidly decreased as the tumour consistently grew. Although $\mathrm{CD}^{+}$and $\mathrm{CD} 8^{+} \mathrm{T}$ cells were high in the RelB$\mathrm{KO}$ group, the cell numbers declined as PD-L1 expression increased in tumour cells (Fig. 6f).

Moreover, to examine whether RelB deprivation also inhibits PCa metastasis by downregulating PD-L1, the three tumour cell lines were further injected into mice through the tail vein. Three weeks after the injection, metastatic lung tumours were detected in the control group, but not in the groups injected with RelB-KO tumour cells irrespective of PD-L1 expression in the cells, thus indicating that RelB is critical for PCa metastasis (Fig. 7a). Furthermore, consistent with the reduction in RelB, the PD-L1 levels also decreased in the RelB-KO group but increased in the PD-L1-expressing group (Fig. 7b-c). Accordingly, $\mathrm{CD}^{+}{ }^{+}$and $\mathrm{CD}^{+} \mathrm{T}$ cell numbers in serum increased in mice injected with RelB-KO RM-1 cells, but the $\mathrm{T}$ cell number decreased in injected mice by restoring PD-L1 in RM-1 cells (Fig. 7d). Taken together, the results from the present study delineated that the high levels of RelB in advanced PCa cells promote immune evasion by transcriptional upregulation of PD-L1, as illustrated in Fig. 7e.

\section{Discussion}

Although the 5-year survival rates of PCa have steadily increased in the United States, the mortality of PCa has been consistently increasing globally, particularly in East Asia [2]. Moreover, AR-negative metastatic PCa displays resistance to the most common treatments and leads to poor prognosis; in particular, devastating bone metastasis appears to be a salient and daunting challenge in the control of PCa [36]. Thus, a comprehensive therapeutic strategy in combination with innovative technologies urgently needs to conquer intractable malignant $\mathrm{PCa}$. In this regard, the advantages of novel cancer immunotherapy have emerged as a prospective method for treating worsened tumours, including advanced PCa [10, 37].

Mounting evidence has demonstrated that immune checkpoint inhibitors have significantly improved overall survival for subsets of patients with malignant tumours that mostly resist traditional anticancer therapies [38, 39]. For instance, the therapeutic effects of the blockade of PD-1/PDL-1 and CTLA-4 checkpoints have been adopted to treat various cancers $[40,41]$. PD-L1 is uniquely expressed at high levels in cancers; therefore, therapies targeting PD-1/PD-L1 have been shown to promote remarkable antitumour immunity and acquire promising therapeutic outcomes for several malignant tumours [14, 42]. Likewise, PD-L1 is profoundly expressed in tumour tissues from mCRPC patients, which suggests that PD-L1 is associated with PCa progression [43]. Although anti-PD-1 treatment has shown therapeutic results for treating primary $\mathrm{PCa}$, the combination of anti-PD-1 mAb with myeloid-derived suppressor cell (MDSC)-targeted therapy has received a robust synergistic therapeutic response in the treatment of mCRPC [44]. Nevertheless, less response to anti-PD-L1 agents in metastatic urothelial cancer and mCRPC suggested stromal TGF- $\beta$ dampening the PD-1/ PD-L1 blockade therapy, which indicates the existence of alternative immunosuppressive mechanisms provided from the tumour microenvironment $[45,46]$.

It is recognized that pro-inflammatory cytokines produced in the tumour microenvironment induce PD-L1 expression in tumour cells $[47,48]$. In particular, IFN- $\gamma$ has been defined as a favourable adaptive immune resistance inducer. Other oncogenic cytokines are also involved in inducing PD-L1 expression, including TGF- $\beta$, IL-6, IL-10, and IL-17 [18]. Mechanistically, the expression of PD-L1 in tumour cells can be regulated through transcriptional and posttranscriptional regulation [17]. Several cytokine/chemokine-inducible transcription 


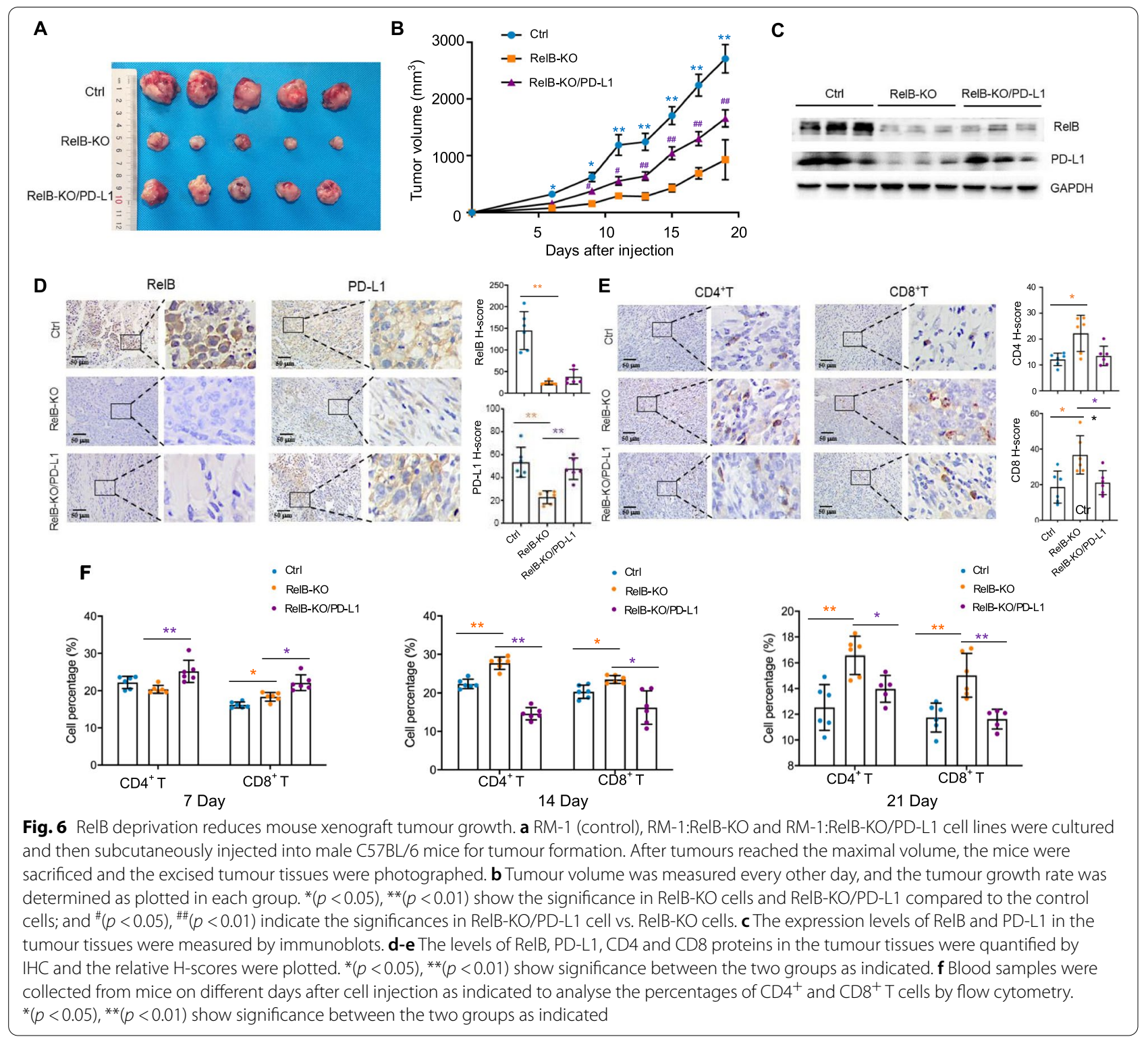

factors have been shown to participate in the regulation of PD-L1, such as Myc, NF-кB, Stat3, and Jun/Ap-1 [18, 49]. Additionally, tumour-suppressive miR-34a appeared to directly downregulate PD-L1 [50], while oncogenic miR-21 seemed to indirectly upregulate PD-L1 via activation of the PI3K-Akt signalling axis by inhibiting PTEN [51]. Furthermore, a recent study demonstrated that AKT upregulates PD-L1 by phosphorylating $\beta$-catenin and promotes glioblastoma immune evasion [52].

Transcriptional regulation plays a pivotal role in $\mathrm{PCa}$ progression. AR-mediated transcriptional regulation plays a fundamental role in the promotion of AR-dependent PCa [53]. Nevertheless, PCa patients frequently receive androgen deprivation and AR-inhibitory therapies, and the AR response is ultimately eradicated in the developed AR-negative malignancy $[54,55]$. Notably, NF- $k B$-mediated transcriptional regulation, in turn, to be activated in $\mathrm{mCRPC}$, functionally sustains PCa progression under androgen-free conditions [56]. Although the activation of the RelA-based canonical NF- $\mathrm{kB}$ pathway has been involved in $\mathrm{PCa}$ progression and therapeutic resistance $[57,58]$, the role of the RelB-based noncanonical NF-кB pathway is underestimated.

RelA has been reported to upregulate PD-L1 in tumour cells in response to TNF- $\alpha$ and LPS stimulation or by cooperation with RB phosphorylation $[20,59,60]$. Nevertheless, there is a lack of current evidence that p50/ RelA directly binds to the NF- $\mathrm{kB}$ element located in the 

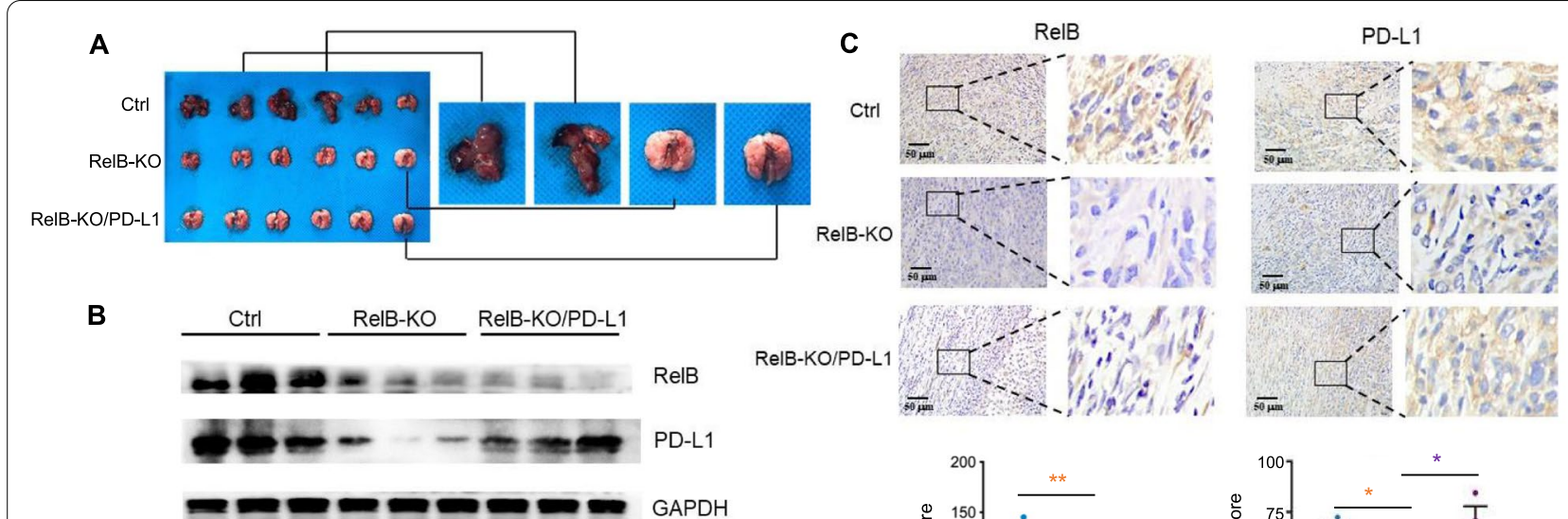

D
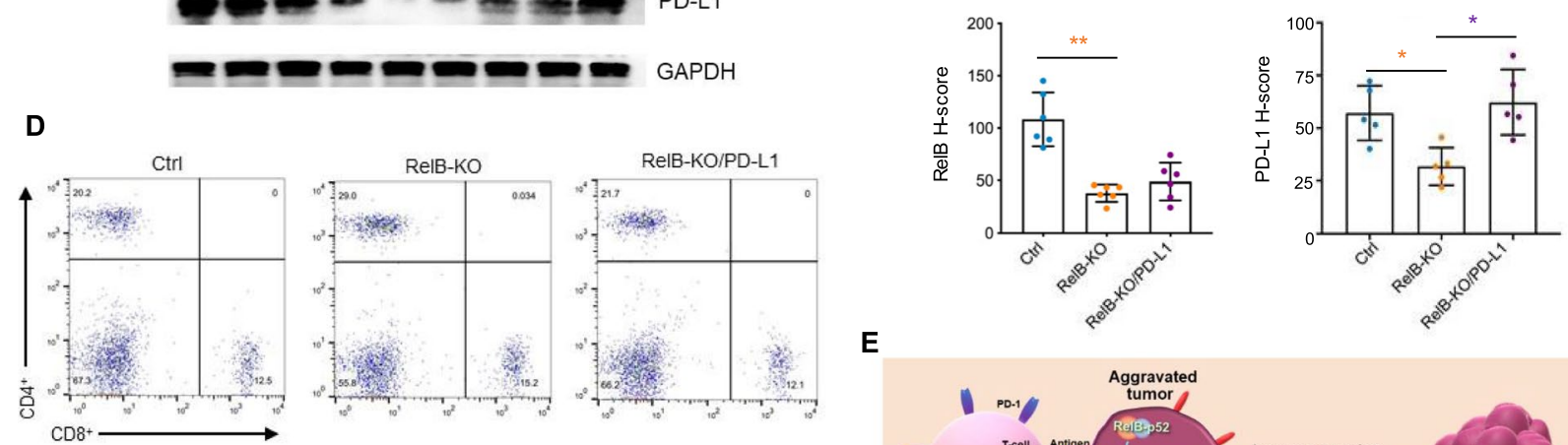

E
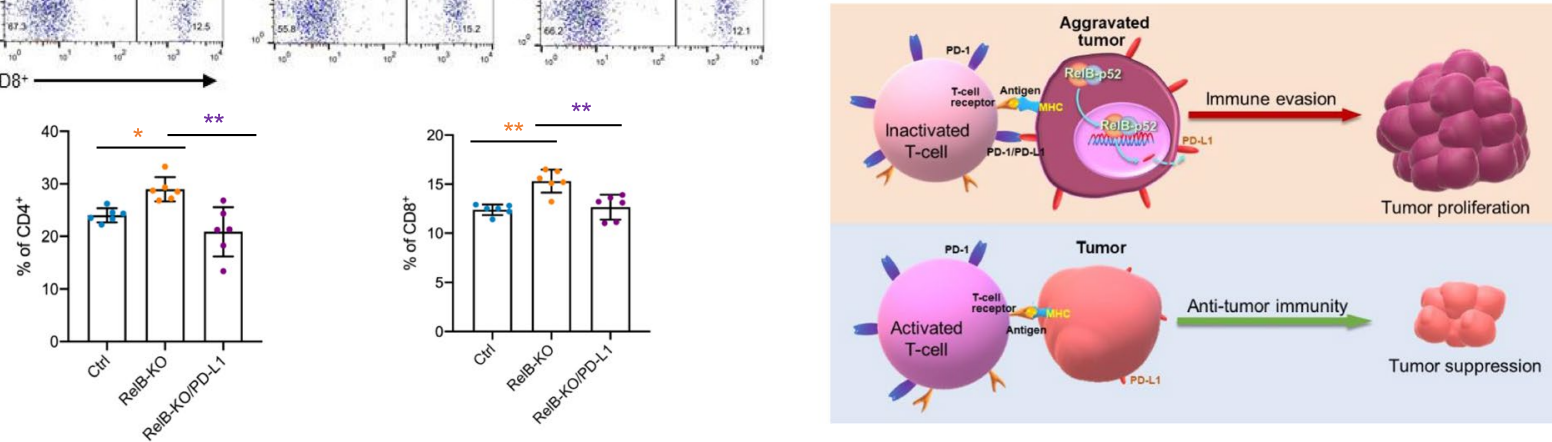

Fig. 7 RelB deprivation decreases mouse xenograft tumour lung metastasis. a RM-1 and its generated cell lines were intravenously injected into male C57BL/6 mice. Lung tissues with tumours in the control group and without tumours in the RelB-KO groups were excised and examined. $\mathbf{b}$ The expression levels of RelB and PD-L1 in the excised tissues were measured by immunoblots. c Additionally, the expression of RelB and PD-L1 was further quantified by $\mathrm{IHC}$ and the relative $\mathrm{H}$-scores were plotted. $\mathbf{d}$ The percentages of $\mathrm{CD} 4^{+}$and $\mathrm{CD} 8^{+} \mathrm{T}$ cells derived from mouse blood samples were analysed by flow cytometry. ${ }^{*}(p<0.05),{ }^{* *}(p<0.01)$ show significance between the two groups as indicated. e Depiction of the suggested mechanism underlying RelB-mediated immune evasion of PCa cells

CD274 promoter. Recently, Antonangeli et al. predicted the canonical NF- $\mathrm{kB}$ consensus sequence in the CD274 promoter region as $5^{\prime}$-GGGRNWYYCC-3' (where R: A/G, W: A/T, Y: C/T, N: any base) [61]; however, the proposed site has yet not fully validated. The present study used the standard NF- $\mathrm{kB}$ consensus sequence (5'-GGGRNYYYCC-3') to search the potential NF- $\mathrm{kB}$ binding site in the $C D 274$ promoter. Three putative sites were validated using a systemic cis/trans transcriptional regulatory approach. The results delineated that a proximal NF- $\mathrm{KB}$ enhancer element located in the core promoter region is responsive to RelB-mediated $\mathrm{PCa}$ immune evasion by upregulating PD-L1. Consistently, the silencing of tumourous RelB led to enhanced $\mathrm{T}$ cell immunity in the suppression of PCa.

Notably, the RelB-based noncanonical NF-kB pathway has been implicated in diverse biological processes, including immunogenicity and tumorigenicity [62]. RelB function is critical for normal B cell maturation and lymphoid organogenesis $[63,64]$. BAFF-NIK-p52/RelB axis is essential for B cell survival by upregulating Bcl-2 and Bclxl [65]. Additionally, TRAF3- or NIK-deficiency appeared to preclude $\mathrm{T}$ cell function by inhibiting the noncanonical NF- $\mathrm{KB}$ pathway $[66,67]$. Intriguingly, the results from this study elucidated, for the first time, that tumour-derived RelB hampers T cell function by upregulating PD-L1. Thus, the implication of RelB in both immune cells and tumour 
cells has emerged as a major concern for tumour immunotherapy. Taken together, insight into RelB-mediated PD-L1 overexpression is anticipated to provide a promising approach for enhancing immune checkpoint blockade therapy through the administration of RelB.

\section{Conclusion}

In summary, this study delineated that RelB participates in the regulation of PD-L1 in PCa cells. RelB and PD-L1 are highly expressed in advanced $\mathrm{PCa}$ and contribute to immune evasion. The silencing of RelB led to reduced PD-L1 expression and enhanced $\mathrm{T}$ cell immune response. Furthermore, RelB upregulates PD-L1 in response to cytokines, mainly through binding to a proximal NF-kB element located in the core promoter region of the $C D 274$ gene.

\begin{abstract}
Abbreviations
PCa: Prostate cancer; $m$ CRPC: Metastatic castration-resistant prostate cancer; TCGA: The Cancer Genome Atlas; PD-1: Programmed death receptor; PD-L1: A ligand of PD-1; CTLA-4: Cytotoxic T lymphocyte-associated antigen-4; NF-KB: Nuclear factor kappa light chain enhancer of activated B cells; IFN- $\mathbf{~ : ~ H u m a n ~}$ interferon-gamma; TNF-a: Tumour necrosis factor alpha; IL-2: Interleukin-2; shRNA: Small hairpin RNA; KO: Knockout; IHC: Immunohistochemistry; RNAseq: RNA sequencing; RT-qPCR: Reverse transcription-quantitative PCR; ChIP: Chromatin immunoprecipitation; EMSA: Electrophoretic mobility shift assay; RBC: Red blood cells.
\end{abstract}

\section{Supplementary Information}

The online version contains supplementary material available at https://doi. org/10.1186/s13046-022-02243-2.

\section{Additional file 1. \\ Additional file 2 . \\ Additional file 3. \\ Additional file 4. \\ Additional file 5 . \\ Additional file 6.}

Additional file 7.

Additional file 8

Additional file 9.

\section{Acknowledgements}

The authors thank Dr. Hongbing Shen, Director of Cancer Research Cancer at Nanjing Medical University, for providing most research resources to support this study.

\section{Authors' contributions}

YZ designed and carried out experiments, participated in data interpretation and drafted the manuscript. SZ carried out experiments and data analysis. YD performed the additional experiments required in the revision. FX participated in the preparation of experimental materials. WS performed bioinformatics and gene transcriptional analysis. ZX participated in data analysis and figure design. XW participated in data statistical analysis. PQ participated in the experimental performance. QZ participated in coordination and technical support. JF provided administrative and material supports. YX designed and supervised the study, participated in the writing and revision of the manuscript. All authors read and approved the final manuscript.

\section{Funding}

This study was supported by the National Natural Science Foundation of China Research Grants (Nos. 81572742 and 81972742) and the National Program on Key Research Project of China (No. 2016YFC0905900) to Xu Y; Jiangsu Postdoctoral Research Foundation (No. 2021K206B) to Zhang Y; Jiangsu Provincial Key Research Development Program (BE 2017759) to Qin Zhang.

\section{Availability of data and materials}

All data relevant to this study are included in the article and accessible online supplemental information. Data are available in a public, open access repository. Materials included in this study will be available for reasonable request to the corresponding author, Prof. Yong Xu.

\section{Declarations}

\section{Ethics approval and consent to participate}

Written informed consent was obtained from patients enrolled in this study based on the guidelines of the human study declaration issued by the medical ethics committee of Nanjing Medical University.

\section{Consent for publication}

All authors provided their consent to publish the study.

\section{Competing interests}

The authors declare no competing interests.

\section{Author details}

${ }^{1}$ Laboratory of Cancer Biology, Jiangsu Cancer Hospital \& Jiangsu Institute of Cancer Research \& the Affiliated Cancer Hospital of Nanjing Medical University, Nanjing 210009, China. ${ }^{2}$ Jiangsu Key Lab of Cancer Biomarkers, Prevention and Treatment, Nanjing Medical University, Nanjing 211166, China. ${ }^{3}$ Department of Medical Oncology, the Affiliated Cancer Hospital of Nanjing Medical University, Jiangsu Cancer Hospital \& Jiangsu Institute of Cancer Research, Nanjing 210009, China. ${ }^{4}$ Department of General Surgery, the First Affiliated Hospital with Nanjing Medical University, Nanjing 210029, China. ${ }^{5}$ Department of Surgery, Jiangsu Cancer Hospital \& Jiangsu Institute of Cancer Research \& the Affiliated Cancer Hospital of Nanjing Medical University, Nanjing 210009, China.

Received: 2 September 2021 Accepted: 31 December 2021

Published online: 17 February 2022

\section{References}

1. Culp MB, Soerjomataram I, Efstathiou JA, Bray F, Jemal A. Recent global patterns in prostate Cancer incidence and mortality rates. Eur Urol. 2020;77:38-52.

2. Miller KD, Nogueira L, Mariotto AB, Rowland JH, Yabroff KR, Alfano CM, et al. Cancer treatment and survivorship statistics, 2019. CA Cancer J Clin. 2019;69:363-85.

3. Criscuolo D, Morra F, Giannella R, Cerrato A, Celetti A. Identification of novel biomarkers of homologous recombination defect in DNA repair to predict sensitivity of prostate Cancer cells to PARP-inhibitors. Int J Mol Sci. 2019;20.

4. Morra F, Merolla F, Criscuolo D, Insabato L, Giannella R, llardi G, et al. CCDC6 and USP7 expression levels suggest novel treatment options in high-grade urothelial bladder cancer. J Exp Clin Cancer Res. 2019;38:90.

5. Criscuolo D, Morra F, Giannella R, Visconti R, Cerrato A, Celetti A. New combinatorial strategies to improve the PARP inhibitors efficacy in the urothelial bladder Cancer treatment. J Exp Clin Cancer Res. 2019;38:91.

6. Yang Y. Cancer immunotherapy: harnessing the immune system to battle cancer. J Clin Invest. 2015:125:3335-7.

7. Kwek SS, Cha E, Fong L. Unmasking the immune recognition of prostate cancer with CTLA4 blockade. Nat Rev Cancer. 2012;12:289-97.

8. Pitt JM, Vetizou M, Daillere R, Roberti MP, Yamazaki T, Routy B, et al. Resistance mechanisms to immune-checkpoint blockade in Cancer: tumorintrinsic and -extrinsic factors. Immunity. 2016;44:1255-69.

9. Goodman A, Patel SP, Kurzrock R. PD-1-PD-L1 immune-checkpoint blockade in B-cell lymphomas. Nat Rev Clin Oncol. 2017;14:203-20. 
10. Brahmer JR, Tykodi SS, Chow LQ, Hwu WJ, Topalian SL, Hwu P, et al. Safety and activity of anti-PD-L1 antibody in patients with advanced cancer. N Engl J Med. 2012;366:2455-65.

11. Okazaki T, Chikuma S, Iwai Y, Fagarasan S, Honjo T. A rheostat for immune responses: the unique properties of PD-1 and their advantages for clinical application. Nat Immunol. 2013;14:1212-8.

12. Zak KM, Grudnik P, Magiera K, Domling A, Dubin G, Holak TA. Structural biology of the immune checkpoint receptor PD-1 and its ligands PD-L1/ PD-L2. Structure. 2017:25:1163-74.

13. Webb JR, Milne K, Kroeger DR, Nelson BH. PD-L1 expression is associated with tumor-infiltrating T cells and favorable prognosis in high-grade serous ovarian cancer. Gynecol Oncol. 2016;141:293-302.

14. Casey SC, Tong L, Li Y, Do R, Walz S, Fitzgerald KN, et al. MYC regulates the antitumor immune response through CD47 and PD-L1. Science. 2016;352:227-31.

15. Tumeh PC, Harview $C L$, Yearley JH, Shintaku IP, Taylor EJ, Robert L, et al. PD-1 blockade induces responses by inhibiting adaptive immune resistance. Nature. 2014;515:568-71.

16. Platanias LC. Mechanisms of type-I- and type-II-interferon-mediated signalling. Nat Rev Immunol. 2005;5:375-86.

17. Sun C, Mezzadra R, Schumacher TN. Regulation and function of the PD-L1 checkpoint. Immunity. 2018;48:434-52.

18. Cha JH, Chan LC, Li CW, Hsu JL, Hung MC. Mechanisms controlling PD-L1 expression in Cancer. Mol Cell. 2019;76:359-70.

19. Ben-Neriah Y, Karin M. Inflammation meets cancer, with NF-kappaB as the matchmaker. Nat Immunol. 2011;12:715-23.

20. Asgarova A, Asgarov K, Godet Y, Peixoto P, Nadaradjane A, Boyer-Guittaut $M$, et al. PD-L1 expression is regulated by both DNA methylation and NF-kB during EMT signaling in non-small cell lung carcinoma. Oncoimmunology. 2018;7:e1423170.

21. Karin M. NF-kappaB and cancer: mechanisms and targets. Mol Carcinog. 2006;45:355-61.

22. Hayden MS, Ghosh S. Shared principles in NF-kappaB signaling. Cell. 2008;132:344-62.

23. Sun SC. Non-canonical NF-kappaB signaling pathway. Cell Res. 2011;21:71-85.

24. van Delft MA, Huitema LF, Tas SW. The contribution of NF-kappaB signalling to immune regulation and tolerance. Eur J Clin Investig. 2015;45:529-39.

25. Burkly L, Hession C, Ogata L, Reilly C, Marconi LA, Olson D, et al. Expression of relB is required for the development of thymic medulla and dendritic cells. Nature. 1995;373:531-6.

26. Weih F, Carrasco D, Durham SK, Barton DS, Rizzo CA, Ryseck RP, et al. Multiorgan inflammation and hematopoietic abnormalities in mice with a targeted disruption of RelB, a member of the NF-kappa B/Rel family. Cell. 1995;80:331-40.

27. Sun SC. The non-canonical NF-kappaB pathway in immunity and inflammation. Nat Rev Immunol. 2017;17:545-58.

28. Ge QL, Liu SH, Ai ZH, Tao MF, Ma L, Wen SY, et al. RelB/NF-kappaB links cell cycle transition and apoptosis to endometrioid adenocarcinoma tumorigenesis. Cell Death Dis. 2016;7:e2402.

29. Wang $M$, Zhang $Y, X u Z$, Qian P, Sun W, Wang $X$, et al. RelB sustains endocrine resistant malignancy: an insight of noncanonical NF-kappaB pathway into breast Cancer progression. Cell Commun Signal. 2020;18:128.

30. Xu Y, Josson S, Fang F, Oberley TD, St Clair DK, Wan XS, et al. RelB enhances prostate cancer growth: implications for the role of the nuclear factor-kappaB alternative pathway in tumorigenicity. Cancer Res. 2009:69:3267-71.

31. Zhang Y, Xu Z, Ding J, Tan C, Hu W, Li Y, et al. HZO8 suppresses RelBactivated MnSOD expression and enhances Radiosensitivity of prostate Cancer cells. J Exp Clin Cancer Res. 2018;37:174.

32. Peng J, Hamanishi J, Matsumura N, Abiko K, Murat K, Baba T, et al. Chemotherapy induces programmed cell death-ligand 1 overexpression via the nuclear factor-kappaB to Foster an immunosuppressive tumor microenvironment in ovarian Cancer. Cancer Res. 2015;75:5034-45.

33. Wang W, Chapman NM, Zhang B, Li M, Fan M, Laribee RN, et al. Upregulation of PD-L1 via HMGB1-activated IRF3 and NF-kappaB contributes to UV radiation-induced immune suppression. Cancer Res. 2019;79:2909-22.

34. Borst J, Ahrends T, Babala N, Melief CJM, Kastenmuller W. CD4(+) T cell help in cancer immunology and immunotherapy. Nat Rev Immunol. 2018;18:635-47.

35. Farhood B, Najafi M, Mortezaee K. CD8(+) cytotoxic T lymphocytes in cancer immunotherapy: a review. J Cell Physiol. 2019;234:8509-21.
36. Berish RB, Ali AN, Telmer PG, Ronald JA, Leong HS. Translational models of prostate cancer bone metastasis. Nat Rev Urol. 2018;15:403-21.

37. Isaacsson Velho P, Antonarakis ES. PD-1/PD-L1 pathway inhibitors in advanced prostate cancer. Expert Rev Clin Pharmacol. 2018;11:475-86.

38. Qin S, Xu L, Yi M, Yu S, Wu K, Luo S. Novel immune checkpoint targets: moving beyond PD-1 and CTLA-4. Mol Cancer. 2019;18:155.

39. Palucka AK, Coussens LM. The basis of Oncoimmunology. Cell. 2016;164:1233-47.

40. Darvin P, Toor SM, Sasidharan Nair V, Elkord E. Immune checkpoint inhibitors: recent progress and potential biomarkers. Exp Mol Med. 2018;50:1-11.

41. Ott PA, Hodi FS, Robert C. CTLA-4 and PD-1/PD-L1 blockade: new immunotherapeutic modalities with durable clinical benefit in melanoma patients. Clin Cancer Res. 2013;19:5300-9.

42. Chen L, Han X. Anti-PD-1/PD-L1 therapy of human cancer: past, present, and future. J Clin Invest. 2015;125:3384-91.

43. Gevensleben H, Dietrich D, Golletz C, Steiner S, Jung M, Thiesler T, et al. The immune checkpoint regulator PD-L1 is highly expressed in aggressive primary prostate Cancer. Clin Cancer Res. 2016;22:1969-77.

44. LuX, Horner JW, Paul E, Shang X, Troncoso P, Deng P, et al. Effective combinatorial immunotherapy for castration-resistant prostate cancer. Nature. 2017;543:728-32.

45. Mariathasan S, Turley SJ, Nickles D, Castiglioni A, Yuen K, Wang Y, et al. TGFbeta attenuates tumour response to PD-L1 blockade by contributing to exclusion of T cells. Nature. 2018;554:544-8.

46. Jiao S, Subudhi SK, Aparicio A, Ge Z, Guan B, Miura Y, et al. Differences in tumor microenvironment dictate Thelper lineage polarization and response to immune checkpoint therapy. Cell. 2019;179:1177-90 e1113.

47. Lim SO, Li CW, Xia W, Cha JH, Chan LC, Wu Y, et al. Deubiquitination and stabilization of PD-L1 by CSN5. Cancer Cell. 2016;30:925-39.

48. Chen S, Crabill GA, Pritchard TS, McMiller TL, Wei P, Pardoll DM, et al. Mechanisms regulating PD-L1 expression on tumor and immune cells. J Immunother Cancer. 2019;7:305.

49. Ritprajak P, Azuma M. Intrinsic and extrinsic control of expression of the immunoregulatory molecule PD-L1 in epithelial cells and squamous cell carcinoma. Oral Oncol. 2015;51:221-8.

50. Anastasiadou E, Stroopinsky D, Alimperti S, Jiao AL, Pyzer AR, Cippitelli C, et al. Epstein-Barr virus-encoded EBNA2 alters immune checkpoint PD-L1 expression by downregulating miR-34a in B-cell lymphomas. Leukemia. 2019;33:132-47.

51. Xi J, Huang Q, Wang L, Ma X, Deng Q, Kumar M, et al. Young KH, et al: miR-21 depletion in macrophages promotes tumoricidal polarization and enhances PD-1 immunotherapy. Oncogene. 2018;37:3151-65.

52. Du L, Lee JH, Jiang H, Wang C, Wang S, Zheng Z, et al. Li J, et al: betacatenin induces transcriptional expression of PD-L1 to promote glioblastoma immune evasion. J Exp Med. 2020;217.

53. Dai C, Heemers H, Sharifi N. Androgen signaling in prostate Cancer. Cold Spring Harb Perspect Med. 2017;7.

54. Laudato S, Aparicio A, Giancotti FG. Clonal evolution and epithelial plasticity in the emergence of AR-independent prostate carcinoma. Trends Cancer. 2019;5:440-55.

55. Sowalsky AG, Ye H, Bhasin M, Van Allen EM, Loda M, Lis RT, et al. Neoadjuvant-intensive androgen deprivation therapy selects for prostate tumor foci with diverse subclonal oncogenic alterations. Cancer Res. 2018;78:4716-30.

56. Jin R, Yi Y, Yull FE, Blackwell TS, Clark PE, Koyama T, et al. NF-kappaB gene signature predicts prostate cancer progression. Cancer Res. 2014;74:2763-72

57. Grosset AA, Ouellet V, Caron C, Fragoso G, Barres V, Delvoye N, et al. Validation of the prognostic value of NF-kappaB p65 in prostate cancer: a retrospective study using a large multi-institutional cohort of the Canadian prostate Cancer biomarker network. PLoS Med. 2019;16:e1002847.

58. Jeong JH, Park SJ, Dickinson SI, Luo JL. A constitutive intrinsic inflammatory signaling circuit composed of miR-196b, Meis2, PPP3CC, and p65 drives prostate Cancer castration resistance. Mol Cell. 2017;65:154-67.

59. Jin $X$, Ding D, Yan Y, Li H, Wang B, Ma L, et al. Phosphorylated RB promotes Cancer immunity by inhibiting NF-kappaB activation and PD-L1 expression. Mol Cell. 2019;73:22-35 e26.

60. Li H, Xia JQ, Zhu FS, Xi ZH, Pan CY, Gu LM, et al. LPS promotes the expression of PD-L1 in gastric cancer cells through NF-kappaB activation. J Cell Biochem. 2018;119:9997-10004.

61. Antonangeli F, Natalini A, Garassino MC, Sica A, Santoni A, Di Rosa F. Regulation of PD-L1 expression by NF-KB in Cancer. Front Immunol. 2020;11. 
62. Cildir G, Low KC, Tergaonkar V. Noncanonical NF-kappaB signaling in health and disease. Trends Mol Med. 2016;22:414-29.

63. Liu Z, Mar KB, Hanners NW, Perelman SS, Kanchwala M, Xing C, et al. A NIK-SIX signalling axis controls inflammation by targeted silencing of non-canonical NF-kappaB. Nature. 2019;568:249-53.

64. Mukherjee T, Chatterjee B, Dhar A, Bais SS, Chawla M, Roy P, et al. A TNFp100 pathway subverts noncanonical NF-kappaB signaling in inflamed secondary lymphoid organs. EMBO J. 2017;36:3501-16.

65. Claudio E, Brown K, Park S, Wang H, Siebenlist U. BAFF-induced NEMOindependent processing of NF-kappa B2 in maturing B cells. Nat Immunol. 2002;3:958-65.

66. Chang JH, Hu H, Jin J, Puebla-Osorio N, Xiao Y, Gilbert BE, et al. TRAF3 regulates the effector function of regulatory $T$ cells and humoral immune responses. J Exp Med. 2014;211:137-51.

67. Mair F, Joller S, Hoeppli R, Onder L, Hahn M, Ludewig B, et al. The NFkappaB-inducing kinase is essential for the developmental programming of skin-resident and IL-17-producing gammadelta T cells. Elife. 2015;4.

\section{Publisher's Note}

Springer Nature remains neutral with regard to jurisdictional claims in published maps and institutional affiliations.

- fast, convenient online submission

- thorough peer review by experienced researchers in your field

- rapid publication on acceptance

- support for research data, including large and complex data types

- gold Open Access which fosters wider collaboration and increased citations

- maximum visibility for your research: over $100 \mathrm{M}$ website views per year

At BMC, research is always in progress.

Learn more biomedcentral.com/submissions 